\title{
Foreword Symposium on Bulk Metallic Glasses VII
}

In general, bulk metallic glasses (BMGs) exhibit excellent mechanical properties, for example, high strengths (up to 5 GPa), high elastic limits, low Young's moduli, low coefficients of friction, high scratch and wear resistances, good fracture toughness, and good fatigue resistance. Thus, BMGs show a promising potential as structural and engineering materials. BMGs are studied extensively from their fabrication, atomic structure, chemical, and physical properties to their engineering applications.

In order to strengthen the communication in the community of BMGs, a Bulk Metallic Glasses Symposium has been held successfully at The Minerals, Metals \& Materials Society (TMS) Annual Meeting since 2004. The TMS Structural Materials Division and the TMS/American Society for Metals (ASM): Mechanical Behavior of Materials Committee kindly sponsored our Bulk Metallic Glasses Symposium. The Bulk Metallic Glasses VII Symposium was successfully held at the 2010 TMS Annual Meeting \& Exhibition (Seattle, WA, February 14-18, 2010). 103 presentations, including 2 keynotes and 41 invited talks, were given during the meeting. The topics of the Bulk Metallic Glasses Symposium involved a wide range of BMG research areas, such as alloy development and application, glass-forming ability, mechanical behavior, structure characterization, fatigue and corrosion, and simulation and modeling.

In order to maintain the $\mathrm{BMG}$ research activities and intensities, it is of paramount importance to continue the efforts on the applications of BMGs besides conducting the basic research of BMGs. Recently, the exciting news is that Apple was granted the exclusive use of "Liquidmetal" (metallic glass) casing material. Hopefully, the applications of BMGs can be continued in the near future.

We express our sincere appreciation to all the attendees for contributing to the success of our Bulk Metallic Glasses Symposium. We want to acknowledge the sponsors from TMS and ASM. All submitted manuscripts were subjected to the standard peer-review procedures of the journal of Metallurgical and Materials Transactions A. A total of 13 papers were accepted for publication in the current issue. We are very grateful to all the key readers, the reviewers, and the staff of Metallurgical and Materials Transactions A, especially Ms. Dora Moscatello, Ms. Mary Lynn Brown, and Professor David E. Laughlin, for their kind help in the preparation and approval of the Symposium publication.

We greatly acknowledge the financial support of the National Science Foundation (NSF) through (1) the International Materials Institutes (IMI) under DMR-0231320, (2) the Combined Research and Curriculum Development (CRCD) Programs under EEC-9527527 and EEC-0203415, (3) the Division of Civil, Mechanical, Manufacture, and Innovation Program under CMMI-0900271, and (4) the Materials World Network Program under DMR-0909037 at The University of Tennessee, Knoxville (UTK), with Dr. C. Huber, Ms. M. Poats, Dr. C.V. Cooper, Dr. A. Ardell, and Dr. D. Finotello of NSF as the program directors, respectively. The financial support from the Center for Materials Processing (CMP) at UTK with Dr. C.J. McHargue as the director is sincerely acknowledged.

Symposium Organizers

Peter K. Liaw

The University of Tennessee

Gongyao Wang

The University of Tennessee

Hahn Choo

The University of Tennessee

Yanfei Gao

The University of Tennessee 